\title{
A critical review on waste paper sorting techniques
}

\author{
M. O. Rahman • A. Hussain $\cdot$ H. Basri
}

Received: 20 September 2012/Revised: 10 January 2013/Accepted: 23 February 2013/Published online: 4 April 2013

(C) Islamic Azad University (IAU) 2013

\begin{abstract}
Efficient waste paper recycling has a significant role in the sustainable environment. Recyclable waste paper as a fundamental ingredient of municipal solid wastes (MSWs) is indeed an "urban ore". Waste papers are considered as the solid recovered fuel which is recovered from MSW. Recyclable waste papers are segregated into various grades to produce high-quality products. Moreover, sorted paper streams save energy, chemicals, and water, as well as reduce sludge and rejects. Information technology is widely integrated with the waste management industry into its operations such as recycling, reuse, segregating based on categories and so on. This review article focuses on the life cycle of waste paper and existing waste paper sorting techniques. In the paper industry, many types of sensors are used in different mechanical and optical waste paper sorting systems. Such sensors include lignin, gloss, stiffness, mid-infrared, infrared, and color sensors. In this review, also described the effectiveness of different waste paper sorting systems, and finally, recommended appropriate waste paper
\end{abstract}

\section{O. Rahman $(\bowtie) \cdot$ A. Hussain}

Department of Electrical, Electronic and Systems Engineering, Faculty of Engineering and Built Environment, Universiti Kebangsaan Malaysia (UKM), 43600 Bangi, Selangor, Malaysia e-mail: osiur.ukm@gmail.com; osiur_rahman@yahoo.com

\section{A. Hussain}

e-mail: aini@eng.ukm.my; drah.ukm@gmail.com

\section{O. Rahman}

Department of Computer Science and Engineering, University of Chittagong, Chittagong 4331, Bangladesh

\section{H. Basri}

Department of Civil and Structural Engineering, Faculty of Engineering and Built Environment, Universiti Kebangsaan Malaysia (UKM), 43600 Bangi, Selangor, Malaysia e-mail: drhb@eng.ukm.my; drhb@ukm.my sorting techniques based on effectiveness and low-cost implementation.

Keywords Waste paper sorting - Paper grade - Template matching $\cdot$ Lignin sensor $\cdot$ Stiffness sensor $\cdot$ Color sensor . Intelligent computer vision

\section{Introduction}

Paper comprises a network of plant fibers laid down as a flat sheet that is made from a suspension of plant tissues in water, known as pulp. Etymologically, "paper" is derived from "papyrus," the Ancient Greek word for Cyperus papyrus. The plant fiber of waste paper is reusable for six to seven times (Villanueva and Wenzel 2007). Hence, the demand for recyclable waste paper is rapidly increasing in the global market of pulp production. Although the total production capacity of all Malaysian paper mills reaches $1,300,000$ tons/year, consumption remains higher than production capacity (Asia Pro Eco Program 2006). The Malaysian pulp and paper industry is heavily dependent on imported fiber, particularly virgin pulp. Hence, the industry has to find a new source of fiber to strengthen and retain the quality of secondary fibers given the growing use of recycled paper in Malaysia. Notably, $90 \%$ of the paper supply is made of recycled fiber (Asia Pro Eco Program 2006; Rahman et al. 2009a).

The recycling of solid wastes such as paper, glass, plastic, and so on, turns wastes into resources and contributes significantly in sustainable environment (Zaman 2010; Chen et al. 2010). Recyclable waste paper as a fundamental ingredient of municipal solid wastes is indeed an "urban ore". Waste papers are considered as the solid recovered fuel (SRF) which is recovered from municipal 
solid waste (MSW). Information technology is widely integrated with the waste management industry into its operations such as recycling, reuse, segregating based on categories and so on (Hannan et al. 2011). The advancement in sensor technology has facilitated the diverse application of various sensors in the real world. Such applications include the detection of environmental, biological, and chemical parameters. Different sensorbased recyclable waste paper sorting systems are reviewed in this article. The review covers the detailed literature on sensor-based waste paper sorting systems, state-of-the-art technology in the paper industry, and on the overall performance of sensor-based recyclable waste paper sorting systems. The remainder of this article is organized as follows: firstly, the next section briefly describes the life cycle of paper. Secondly, introduces the reasons for waste paper sorting. Thirdly, describes the advancement in sensor-based waste paper sorting based on both the literature and the paper industry. Fourthly, discusses the overall performance of different sensor-based waste paper sorting systems, and finally, presents the conclusions.

\section{Life cycle of paper}

Figure 1 illustrates the life cycle of paper primarily based on Ruwaard et al. (1996), Bystrom and Lonnstedt (2000), European Commission (2001), Villanueva and Wenzel (2007), Schmidt et al. (2007), Pati et al. (2008), Ahmed (2010). The paper life cycle covers reforestation, tree/raw material collection, timber extraction (thinning), sawmilling, virgin pulp production, recycled pulp production, paper production, paper consumption, waste paper collection, waste paper separation, landfilling/incineration, and recyclable waste paper sorting. The life cycle of paper is described below:

\section{Raw material collection}

In the life cycle, the first phase starts with the collection of raw materials. Wood, waste paper, non-wood agriculture fiber, and inorganic fibers, such as hemp, cotton, esparto, grass, sugar cane, and bamboo, are used as raw material sources of fibers for papermaking. For virgin fiber, the paper industry depends on reforestation. In most cases, the need for raw materials in virgin paper production will be reduced when the use of waste paper is increased in recycling.

Pulp and paper production

Paper production basically consists of two steps, namely, pulp production and paper production. Pulp production is

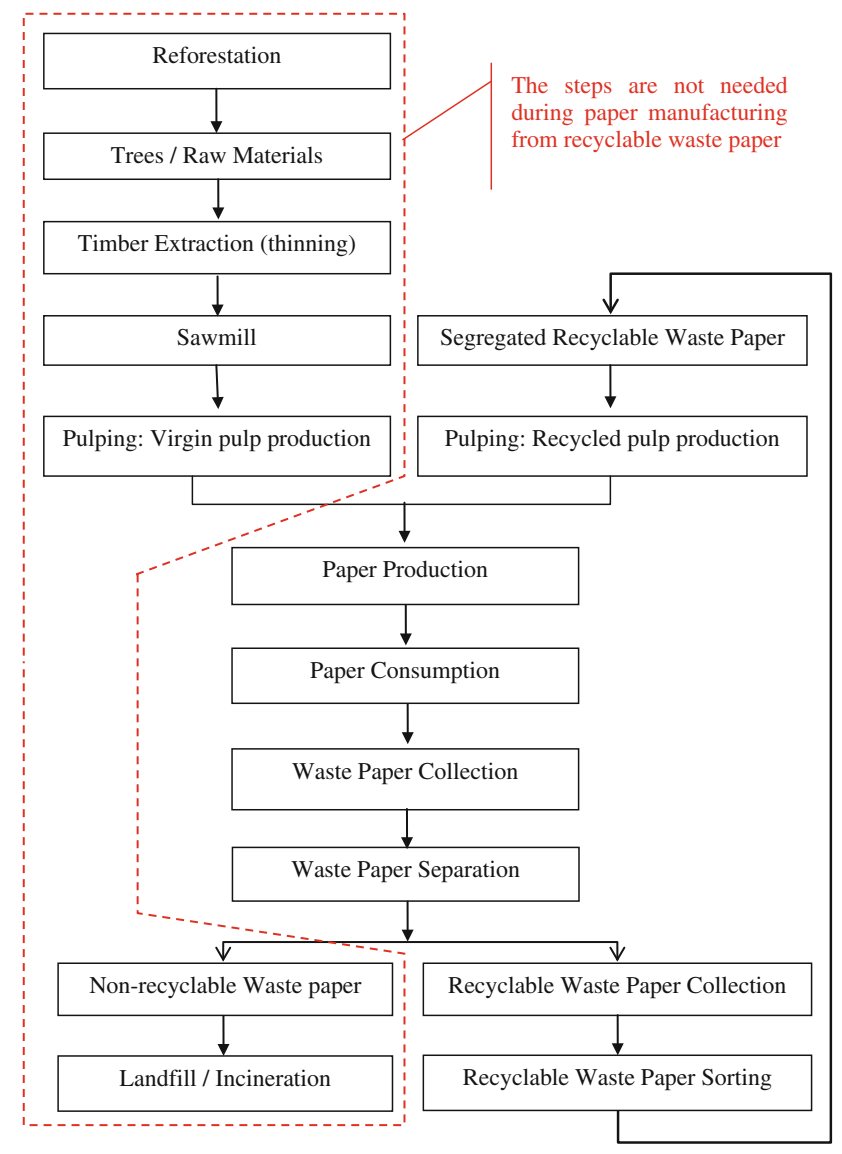

Fig. 1 Life cycle of paper. Source: Ruwaard et al. (1996), Bystrom and Lonnstedt (2000), European Commission (2001), Villanueva and Wenzel (2007), Schmidt et al. (2007), Pati et al. (2008), Ahmed (2010)

further divided into two types, namely, virgin pulp production and recycled pulp production. Both virgin and recycled pulps are used in paper production.

\section{Virgin pulp production}

In virgin pulp production, wood is processed using either a chemical process, a mechanical process, or a semimechanical process.

Chemical pulping The Kraft process is one of the most dominant chemical processes. In this process, wood chips are cooked in sodium-based liquor under pressure. Wood fibers are released from the wood through chemical pulping. Lignin is dissolved from the fiber through chemical pulping until the fibers contain almost no lignin. The Kraft process has numerous advantages; the pulps are easily bleached, and the process is economical because the ligninrich liquor can be reused to generate steam and electricity, thus reducing the consumed energy at the pulp and paper mill. The Kraft process has one major disadvantage, that is, 
the extraction of lignin and other wood components reduces the pulp yield per ton of wood. Typically, office and Kraft paper are produced based on chemical pulp.

Mechanical pulping (MP) Mechanical pulping uses a mechanical process or a combination of both mechanical and chemical processes to produce pulp with higher fiber quality. Mechanical pulping releases wood fibers from the wood through a grinding process. Thermomechanical pulping (TMP) is the most prominent mechanical pulping process and is performed under heated conditions. TMP is relatively more economical than bleached chemical pulp. However, the process damages the fibers during grinding, compressing and/or heating. Hence, only low-strength paper products, such as newsprint, are produced via mechanical pulping.

\section{Recycled pulp production}

In recycled pulp production, pulp from recyclable waste paper is manufactured by grinding collected waste paper in water. After deinking and the removal of impurities, the pulp is ready for paper production. Waste paper fibers are worn down or downgraded when they undergo recycling. Hence, fibers may be recycled for only six to seven times (Villanueva and Wenzel 2007). Moreover, the addition of virgin pulp is necessary to retain the total stock of paper during recycled paper production from collected waste paper. Waste paper pulping generally requires less energy per ton of pulp than pulping processes that use virgin fibers. In addition, this process saves virgin fiber inputs in paper production. Compared with the chemical pulping of wood from virgin sources, waste paper pulping generates no wood wastes nor dissolved chemicals for energy generation. Consequently, when waste paper utilization is increased, the availability of biomass energy is reduced, and the dependence on purchased energy, such as fossil fuels, increases.

\section{Paper consumption}

Offices, households, and commercial establishments are the three main paper consumption sectors. White papers (WPs) are used for academic purposes; newsprint papers are used in newspaper industries, such as news media; and corrugated cardboards are used in packaging. For commercial purposes, high-grade white papers are mostly used for official documentation. In addition, various types of papers are used for different purposes; for instance, glossy papers are used for magazines. Furthermore, paper use is widely classified into three categories, namely, (1) industrial use (for filtering, packaging, electrical use, and wrapping), (2) cultural use (for printing, writing, newspaper, and currency), and (3) food packaging (for candy wrappers, food wrappers, tea bags, and coffee filters).

Waste paper collection and recycling

The flow of recyclable waste paper is illustrated in Fig. 2. The key entities of the flow of the recyclable waste paper are the vendor-customer, dealer, godown owner, supplier, and the manufacturer/paper factory (Pati et al. 2008). The vendor-customer entity is considered the initial source of waste paper. The end user of the finished paper/paper products stores the paper in a bin or in a collection area for recycling after use. The vendor-customer represents the bin or collection area. The dealer collects the waste paper from vendor-customers. The collected waste paper contains both relevant and non-relevant waste. The dealer supplies the collected waste paper to the godown owner. At this stage, the recyclable and non-recyclable waste papers are segregated. Thereafter, the recyclable waste papers are sorted into categories according to the demand of the paper manufacturer or of the paper industry for appropriate pricing. The supplier collects the relevant waste paper for recycling from the godown owner and supplies it to the paper industry or manufacturers.

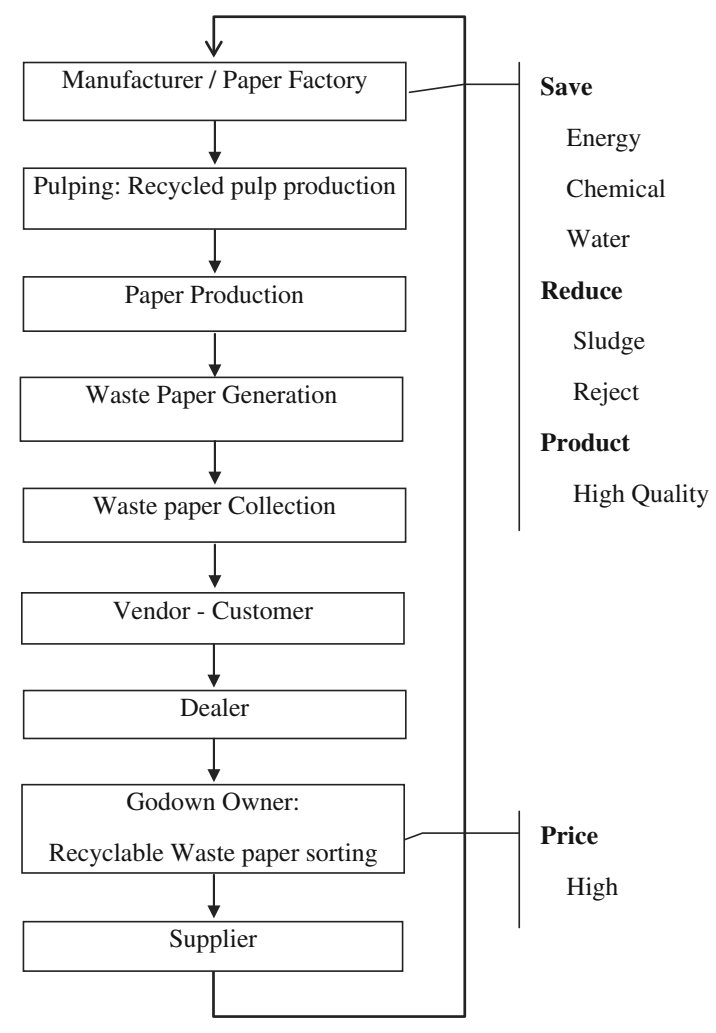

Fig. 2 Flow of the recyclable waste paper 


\section{Driving philosophy behind the waste paper sorting system}

Waste paper sorting is the significant key for achieving the sustainable environment as shown in Fig. 3. In this section, the driving philosophy behind the waste paper sorting system is discussed. Four fundamental issues are covered, namely, the rationale behind waste paper recycling, the justification for waste paper sorting, the economic and environmental effects of waste paper sorting, and the advantages of an automated sorting system.

Rationale behind waste paper recycling

The conservation of resources is a primary concern in ensuring a sustainable environment (Petek and Glavic 1996). Waste paper recycling is one of the key strategies for resource conservation because waste paper constitutes the largest percentage of the office waste stream (Paper Recycling 2010). Moreover, through effective waste paper recycling, any country will benefit from reduced landfilling and will also save money, improve organization image, divert materials from disposal, conserve natural resources, save energy, and reduce greenhouse gas emissions (WasteCap 2008; Paper Recycling 2010). In addition, the manufacturing of one ton of paper from recycled fiber is estimated to save approximately 17 trees, 3.3 cubic yards of landfill space, 360 gallons of water, 100 gallons of gasoline, 60 pounds of air pollutants, and 10,401 kW of electricity (WasteCap 2008; Paper Recycling 2010). Manufacturing paper from virgin timber consumes $60 \%$ more energy than using recycling paper (WasteCap 2008). Recycling office waste paper saves valuable landfill space of approximately 3 cubic yards for every ton of paper recycled, thus extending the lives of landfills. The material that comprises the largest percentage of the waste stream is paper. In Malaysia, over 57,000 tons of paper are thrown into landfills every month, where they occupy $456,000 \mathrm{~m}^{3}$ of landfill space (Paper Recycling 2010).

Pati et al. (2006) revealed that paper recycling is a more economical alternative to wood as a raw material. Laurijssen et al. (2010) concluded that recycling is beneficial in terms of $\mathrm{CO}_{2}$ emissions and (feedstock) energy use over the paper life cycle. Moreover, they showed that the recycling of paper increases biomass availability, which can be utilized for energy generation.

\section{Justification for waste paper sorting}

The primary challenge in paper recycling is the acquisition of raw materials with the highest purity. In recycling, a highly sorted paper stream facilitates a high-quality end product and saves processing chemicals and energy because various grades of paper are subjected to different recycling processes (Laurijssen et al. 2010). In addition, the amount of sludge and rejects generated during recycling is
Fig. 3 Driving philosophy of the waste paper sorting system

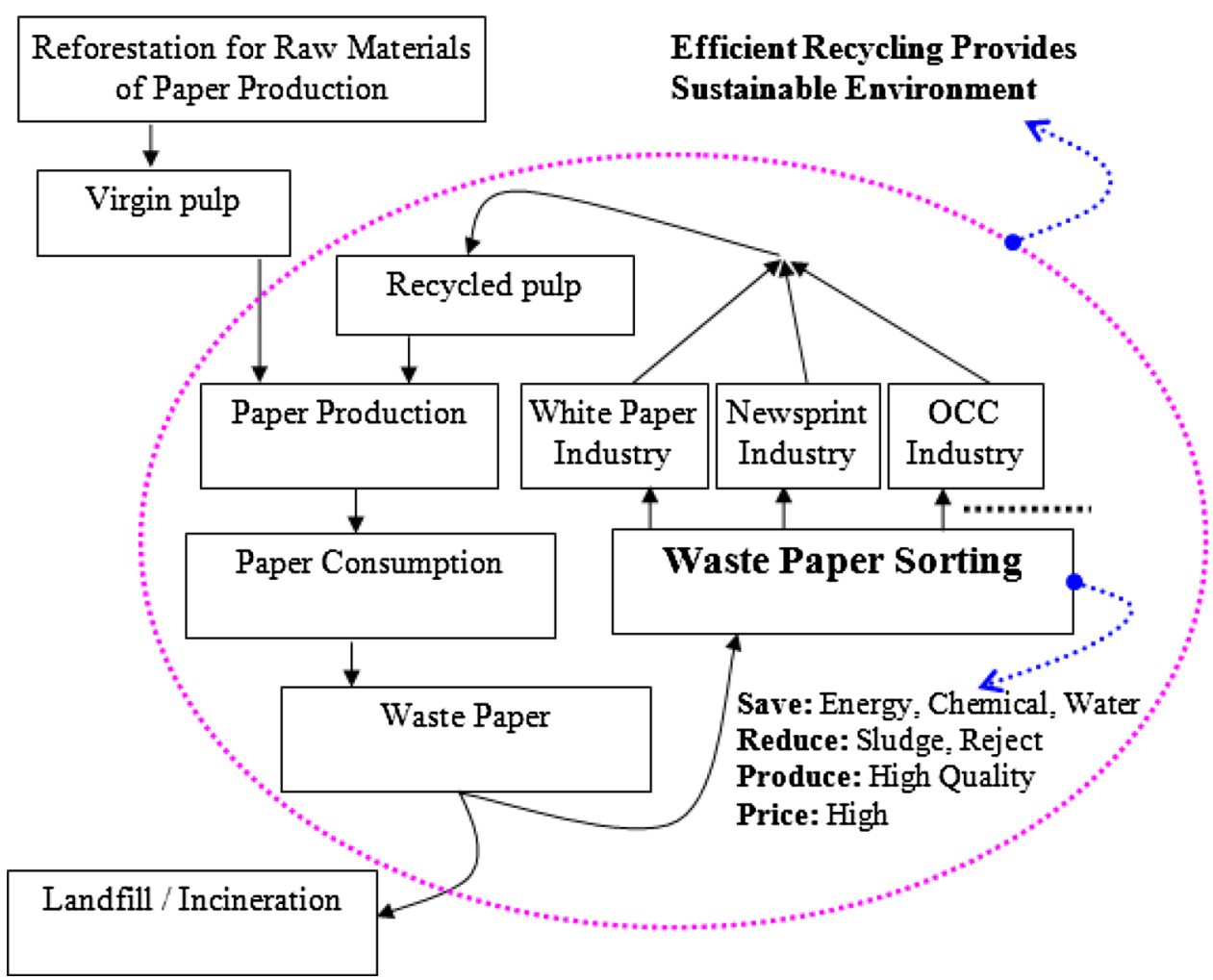


decreased for the utilization of sorted papers in recycling and reduces the amount of water needed to produce recycled paper. In this work, the term "grade" refers to the quality of paper or pulp and is based on weight, color, usage, raw material, surface treatment, finish, or a combination of these factors (Paper Grades 2009).

Economic and environmental effect of waste paper sorting

The reverse distribution network (Pati et al. 2006) for waste paper recycling consists of five entities, namely, the vendor-customer (initial source of waste paper), dealer, godown owner, supplier, and the manufacturer. Waste papers are segregated into different grades in the godown stage of the reverse distribution network (Pati et al. 2006), as shown in Fig. 2. However, society gains at all stages from the economic and environmental perspectives (Ekvall 1999; Pati et al. 2006; Laurijssen et al. 2010). The waste paper purchase rates of Alam Flora Sdn Bhd, one of the leading dealers that collect waste papers in Malaysia, are shown in Table 1. Another company, SPM Paper Recycling Sdn Bhd, sells different grades of paper to paper manufacturing companies at different rates, as shown in Table 2. In the waste paper market, the price of mixed waste paper is always lower than that of segregated waste paper, as indicated in Fig. 4 (Forstall 2002). The amount of $\mathrm{CO}_{2}$ gas emission will be reduced using waste paper pulping (Kayo et al. 2012). In addition, the paper manufacturer will benefit more from segregated waste paper because segregation can facilitate the production of high-quality paper and paper products using less processing chemicals and energy.

\section{Advantages of automated waste paper sorting}

Waste paper sorting systems are classified as either manual or automated systems. In numerous countries, including Malaysia (Paper Recycling 2009), waste papers are sorted into different grades using a manual sorting system. Manual paper sorting faces several major problems. First, manual paper sorting is a labor-intensive industry that incurs a relatively high processing cost. Second, the

Table 1 Waste paper purchase rate of Alam Flora Sdn Bhd

\begin{tabular}{lll}
\hline Paper grade & cents/kg & $1,000 \mathrm{~kg}-\mathrm{RM}$ \\
\hline Newspaper & 24 & 240 \\
Black and white paper & 35 & 350 \\
Carton & 18 & 180 \\
Magazines & 20 & 200 \\
Mix paper & 16 & 160 \\
\hline
\end{tabular}

Source: Information based on personal communication 2010
Table 2 Waste paper sales rate of SPM Paper Recycling Sdn Bhd

\begin{tabular}{lll}
\hline Paper grade & cents/kg & $1,000 \mathrm{~kg}-\mathrm{RM}$ \\
\hline Old corrugated cardboard (OCC) & 32 & 320 \\
Old newsprint (ONP) & 35 & 350 \\
Black white (BW) & 50 & 500 \\
Computer form (CF) & 70 & 700 \\
Mixed white (MW) & 36 & 360 \\
Mixed color (MC) & 20 & 200 \\
White paper (WP) & 95 & 950
\end{tabular}

Source: Information based on personal communication 2009

process has an inconsistent end product quality. Finally, specific skills and commitment are essential for efficient sorting. In addition, laborers working at manual sorting facilities are exposed to microorganisms, organic dust, and fungi, which can cause severe infections (Würtz and Breum 1997). On the other hand, automated paper sorting systems offer significant advantages over manual paper sorting systems in terms of human health, throughput, speed, and accuracy. Hence, the automation of the sorting process is important for efficient, safe, and clean recycling.

\section{Advancement in recyclable waste paper sorting}

Automated paper sorting systems are classified as either mechanical or optical systems. Various mechanical and optical paper sorting methods (Rahman et al. 2011) have been developed to fill the demand for paper sorting. Mechanical paper sorting cannot achieve commercially viable throughputs and accuracy. The greatest advantages of optical paper sorting systems include consistent and reliable production efficiency with a relatively high hit rate and purity, as well as low operational cost because of fewer manual workers on the production line.

The advancement in automated recyclable waste paper sorting consists of three subsections, namely, (1) the review of literature, (2) review of related issues in the paper recycling industry, and (3) the recently proposed webcam sensor-based recyclable waste paper sorting. The review of literature includes published journals, conferences, and patents. The review of related issues in the paper recycling industry focuses on the state-of-the-art technology implemented in the paper recycling industry.

Review of literature

Faibish et al. (1997) proposed an automated paper recycling system in which ultrasonic sound is used to separate different grades of papers. Their proposed system suffered from several problems related to image processing, such as 
Fig. 4 Midwestern waste paper prices (dollars per metric ton, f.o.b. seller's dock). Source: Forstall (2002)

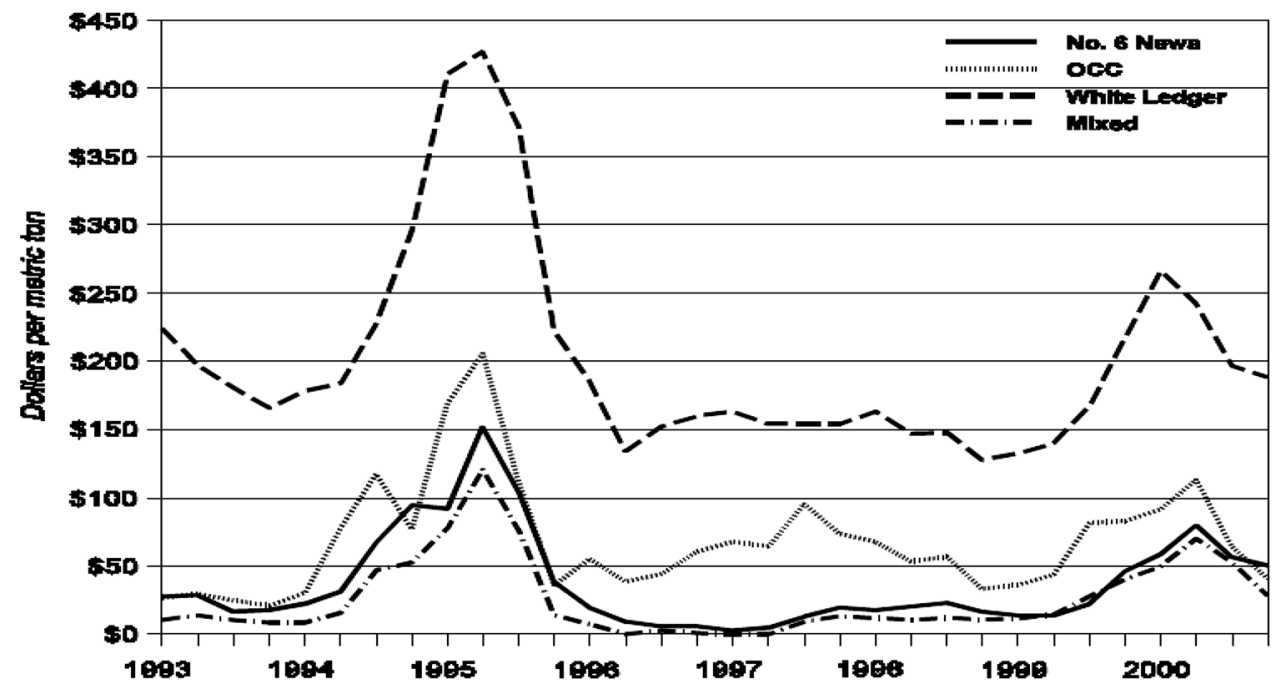

non-uniform illumination, segmentation of dark objects with low reflectance (cloths), and detection of the bounds of the subframes. Furthermore, the adaptive threshold mechanism did not work smoothly for the automatic tuning of the image processing parameters. Moreover, contact manipulation and sensing make the system extremely slow (80 ms/sub-frame) and consequently, impractical for industrial applications.

The lignin sensor was developed for lignin-based waste paper sorting system (Chandini 2001; Karunakaran et al. 2003; Mallapragada 2004; Mallapragada et al. 2004; Ramasubramanian et al. 2005). The lignin sensor works efficiently to separate newsprint samples from other samples. However, lignin sensors are influenced by color and sensor distance from the sample. The red color of office WP produces a normalized voltage matching that of the newsprint (false high), whereas the blue or green color of newsprint produces signals matching those of ledger paper (false low). Consequently, the lignin sensor alone could not detect the presence of newsprint.

Hottenstein et al. (2000) proposed a sensor-based sorting approach in which a brightness sensor (reflected light intensity at $457 \mathrm{~nm}$ ) is used to sort papers primarily into three categories, namely, WPs containing optical brighteners, WPs without optical brighteners, and others. To distinguish further among different colored papers, they described a multigrade sensor that uses gloss and color for identification. The concept of sorting paper based on chemical composition, which is often more important than color, was not addressed in their work.

The stiffness sensor was developed for stiffness sensor-based paper sorting systems that could be used to sort recovered paper into paperboard and others materials (Venditti et al. 2005; Chakravarthi 2006). The stiffness sensor works efficiently in identifying paperboard from other recovered papers (Chakravarthi 2006;
Ramasubrmanian et al. 2007; Venditti et al. 2007). The stiffness sensor sorts recovered paper samples based on their relative stiffness values. The sensor does not actually measure the stiffness of the samples; instead, the amount of deflection of the sample for a given load is used by the sensor to determine the relative stiffness of the sample with respect to other samples. This process is accomplished by creating a lookup table of the deflection values of different kind of samples. However, the sensor could not distinguish between a stack of newsprint and a single paperboard (Ramasubramanian et al. 2008).

Sandberg (1932) proposed a sorting device for waste paper, which sorts waste paper from different types of waste products. The system uses a mechanical process to sort waste paper into paper and others. However, the system could not handle different grades of papers. Bialski et al. $(1978,1980)$ proposed a mechanical process to separate one paper grade from a waste paper mixture. The method of separating dry paper mixture and then retrieving at least one of its components from the remainder of the mixture consisted of the following steps: (a) all components of the mixture are simultaneously subjected to a milling operation, (b) force is applied to the said mixture by scrubbing it against a surface to achieve the progressive fragmentation of the respective components, and (c) paper fragments are finally retrieved.

Ortner et al. (1980) proposed a method for separating paper objects from different foreign matters. In this system, a beater is employed for rough pulping the waste paper. Holz and Hutzler (1986) proposed a waste paper sorting system that segregates paper objects from other foreign matters and then recovers fibers from a stream of waste paper. Similar to other mechanical processes, their system is incapable of handling different grades of papers. Spencer (1994) proposed one mechanical system for the processing of waste paper after the removal of contaminants. 
Likewise, the system is incapable of handling different grades of papers.

Grubbs et al. (2001) proposed waste paper handling and sorting devices and methods. The handling devices accelerate and spread paper from a paper input to a sensor using mechanical processes. Operably thin layers of paper are passed through a sensor at cost-effective feed rates. The paper grades were sorted into two classes, namely, bright WP and others, based on the fluorescent additives in the paper. The attempts by Bialski et al. $(1978,1980)$ and Grubbs et al. (2001) were unsuccessful mainly because of the absence of reliable sensing systems that distinguish among paper grades.

Khalfan (2002) introduced an optical paper sorting method that used diffuse reflectance to identify a sheet of paper as either white or non-white. After a minor modification, Khalfan and Greenspan (2006a, b) proposed two more patented systems using the same methodology. Their proposed paper sorting system segregates papers into white and ground wood paper based on the lignin content. Their invention provided a method for differentiating between a material containing less than or more than a certain amount of lignin based on the following steps:

- light consisting of an ultraviolet component is emitted to strike the material;

- an ultraviolet component of the light diffusely reflected off the material is detected;

- an electrical signal proportional to an intensity of detected ultraviolet light is generated;

- a level of the electrical signal is measured; and

- the level of the electrical signal is compared with a reference level to determine the lignin content of the material.

Eixelberger et al. (2003) proposed an optical paper sorting method to separate waste paper into two classes based on the radiation reflected from the surface of the paper. The method includes the movement of waste paper pieces in the conveying direction on at least one sorting belt. Each waste paper piece has a surface, irradiating at least one area of the surface with radiation. The radiation reflected from the surface is then recorded. Thereafter, the waste paper is sorted based on the reflected radiation, during which waste paper pieces of at least one type are separated from waste paper pieces of at least another type. The apparatus includes at least one sorting conveyor belt for waste paper pieces and at least one radiation source arranged above the sorting belt for irradiating at least one area of the belt. In addition, at least one evaluation device is required to record the radiation reflected from the pieces of waste paper, and at least one sorting device is arranged downstream from at least one radiation source to separate waste paper pieces of at least one type based on the outputs from the evaluation device.
Bruner et al. (2003) proposed one optical paper sorting method to separate waste paper into bright WP and others based on the amount of fluorescence on the surface of the paper objects. The presence or absence of fluorescence is detected by applying ultraviolet light on a sheet of waste paper, detecting light received from the paper in response to the ultraviolet light applied, and then comparing the level of light received from the paper with a threshold to detect the presence or absence of optical brighteners in the paper.

Doak et al. (2006a, b, 2007a, b) proposed optical paper sorting methods to separate different grades of paper based on at least one of several characteristics, including color, glossiness, and presence of printed matter. Paper color is analyzed based on the paper reflectivity of the different wavelengths of visible light. After analysis, the paper is segregated downstream of the inspection zone based on color. To determine the glossiness of paper, two infrared light beams are transmitted from two sources onto the paper. The two light sources are positioned such that diffuse reflected light is received by the sensors from the first light source and directly reflected light is received from the second light source. A comparison of the diffuse reflected first light beam with the directly reflected second light beam is used to analyze the glossiness of the paper. The waste papers are then sorted based on glossiness. To analyze the printed material, light is transmitted onto the paper in the inspection zone. The reflected light is collected from the paper, and the parameters from adjacent portions of the paper within the inspection zone are compared. The reflectance varies in adjacent portions because of the presence of the printed matter on the paper. Thus, paper is also sorted based on the presence of printed matter.

Gschweitl and Heinz (1998) proposed a color-based paper sorting system. Their proposed system utilizes visible light, ultraviolet light, X-rays, and/or infrared light to illuminate the paper and to observe the reflected light using one or more cameras connected to a central processing unit. The implementation of their proposed system is highly expensive because of complexity. Moreover, the system operates at reasonably low speeds because sorting system utilizes a mechanical picker.

Review of related issues in paper recycling industry

Manufacturers Standardization Society (MSS) and TiTech are the top two competitors in sensor-based paper sorting because of the lack of other competitors in the submarket. They possess the required technology and have partnerships with recyclers. MSS and TiTech use near-infrared (NIR) spectroscopy technology and sell their systems in the American, European, Australian, and Asian markets (Paper Competitors 2009). The paper sorting performance is up to 
$80 \%$ for both MSS and TiTech systems (Remade Scotland 2005). Pellenc, Bollegraaf, Lubo, and RedWave are also competitors in the paper submarket.

The TiTech autosort uses the new DUOLINE scanning technology, which conducts a double scan on every pass. The TiTech autosort combines a visual imaging sensor (VIS) and NIR sensors into a universal modular sorting system that meets a wide variety of needs, even highly specialized ones (TITECH autosort 2009). For example, the VIS sensor can be used to recognize print media using cyan, magenta, yellow, and black spectral analysis. PaperSortC, PaperSortCCN, and PaperSortCCN are three TiTech models with conveyor belt widths of 2,000, 1,400, and $2,000 \mathrm{~mm}$ and a sorting capacity of $6-6.5$ tons $/ \mathrm{h}$, 4-4.5 tons $/ \mathrm{h}$, and $6-6.5$ tons $/ \mathrm{h}$, respectively (Remade Scotland 2005).

MSS focuses primarily on the USA and United Kingdom markets and is the only US-based company that provides an automated paper sorting machine. Weyerhauser and MSS partnered to form Automated Sorting Technology LLC to develop an automated paper recycling sorter (Paper Competitors 2009; MSS Paper Sorting Systems 2009). They installed the first PaperSort system in Weyerhauser's Baltimore paper recycling facility and then installed another in Denver (Paper Competitors 2009; MSS Paper Sorting Systems 2009). MSS provides different models for optical paper sorting systems, such as the MultiWave Sensor, FiberSort System, or PaperSort System (MSS Optical sorting Systems 2009). The MSS MultiWave $^{\mathrm{TM}}$ is the automated NIR, color, gloss, and lignin sorting system that is capable of sorting paper and plastics at speeds of $6 \mathrm{~m} / \mathrm{s}(1,200 \mathrm{ft} / \mathrm{min})$ and with $2,400 \mathrm{~mm}$ width $\left(96^{\prime \prime}\right)$. MW 1600-3, MW 2000-3, and MW 2400-3 are the three MultiWave models with machine widths of 1,600 (64"), 2,000 $\left(80^{\prime \prime}\right)$, and 2,400 $\left(96^{\prime \prime}\right) \mathrm{mm}$ and sorting capacities up to $10,12.5$, and 15 tons/h, respectively.

The FiberSort ${ }^{\mathrm{TM}}$ Module is a highly advanced full-color spectrum and NIR sensor that identifies brown old corrugated cardboard (OCC) or containers (OCC) from newsprint and mixed paper grades at high speeds. Single-Eject and Dual-Eject are two FiberSort ${ }^{\mathrm{TM}}$ models with machine widths from 800 to $2,400 \mathrm{~mm}\left(32^{\prime \prime}-96^{\prime \prime}\right)$ and sorting capacities from 3.0 to 9.0 tons $/ \mathrm{h}$. MSS designed the PaperSort system to match the needs of a material recycling facility (MRF) and of a paper processor. The system sorts all grades of paper, and incorporates screens, vibrators, and sensor-based sorting. The PaperSort ${ }^{\mathrm{TM}}$ employs various patented mechanical techniques to reduce burden depth and provide a uniform and single-layer feed stream of paper to the Multi-Grade ${ }^{\mathrm{TM}}$ sensor module. Three types of PaperSort models are designed for three different machine widths, $900\left(36^{\prime \prime}\right), 1,200\left(48^{\prime \prime}\right)$ and 1,800 $\left(72^{\prime \prime}\right) \mathrm{mm}$, with sorting capacities of up to 3, 4, and 6 tons/ h, respectively.

Pellenc, a French company, has recently entered the paper sorting market with two machines, the Zephyr and the Boreas (Pellenc 2009). The Boreas incorporates a new technology called the mid-infrared (MIR) spectroscopy. Pellenc claims that the MIR machine can identify and eject brown, white, and gray cardboard and color print. The detector can also identify materials other than paper, such as plastic and metals with a high efficiency rate. The Zephyr utilizes NIR spectroscopy. Apart from the two paper sorting machines, Pellenc also focuses on the plastics market. Bollegraaf provides recycled machinery equipment and specifically uses Lubo, Red Wave, and TiTech to provide the sorting equipment for MRFs and processors. The German technology in paper sorting is limited to spikes separating cardboard paper from the main stream. Lubo provides star screens to separate paper into cardboard, newspaper, and mixed paper.

RedWave, an Austrian-based company, also provides a technology to sort paper using sensors. In 2003, they developed the technology and partnered with another Austrian company called BT-Wolfgang Binder, a leading manufacturer of recycling equipment (RedWave 2009). They use NIR and color camera technology on all of their machines. Their primary markets are Germany and Eastern Europe. The achieved performance reached up to 8 tons/h for paper and card sorting in Germany in March 2004; up to 6 tons/h for paper and card sorting in Northern Ireland in October 2004; and up to 10 tons/h for paper, cardboard, and plastic sorting in Ireland in June 2005. Despite these performance rates, they did not develop any multigrade paper sorting system, unlike MSS or TiTech.

\section{Computer vision-based/webcam sensor-based waste paper sorting}

As mentioned in "Review of literature" and "Review of related issues in paper recycling industry", eight sensors have been used in paper grade identification systems, namely, ultrasonic (Faibish et al. 1997), lignin (Hottenstein et al. 2000; Chandini 2001; Khalfan 2002; Ramasubramanian et al. 2005; Khalfan and Greenspan 2006a, b), gloss (Hottenstein 2000; Doak et al. 2007a, b), stiffness (Chakravarthi 2006; Venditti et al. 2007; Ramasubramanian et al. 2008), color sensors (Gschweitl and Heinz 1998; Eixelberger et al. 2003; Bruner et al. 2003; Doak et al. 2007a, b; Doak et al. 2007b), NIR, MIR, and VIS. The eight sensors and the respective paper recycling industries are shown in Table 3. Ultrasonic sensors are slow and are thus unsuitable for industry use. The lignin sensor can only be used to separate newsprint paper from others, and its performance is strictly color 
Table 3 List of sensors and paper recycling industries

\begin{tabular}{|c|c|c|}
\hline $\begin{array}{l}\text { Sl. } \\
\text { no. }\end{array}$ & Sensors in industries & Name of the industry \\
\hline 1 & Near infrared (NIR) & $\begin{array}{l}\text { TiTech, MSS, RedWave, } \\
\text { Bollegraaf, Lubo }\end{array}$ \\
\hline 2 & Mid-infrared (MIR) & Pellenc \\
\hline 3 & $\begin{array}{l}\text { Visual imaging sensor } \\
\text { (VIS) }\end{array}$ & TiTech \\
\hline 4 & Ultrasonic sound & Not suitable for industry \\
\hline 5 & Lignin sensor & MSS \\
\hline 6 & Stiffness sensor & MSS \\
\hline 7 & Gloss sensor & MSS \\
\hline 8 & Color sensor & MSS, RedWave, Bollegraaf, Lubo \\
\hline
\end{tabular}

dependent. Lignin-free sheets printed with colors will also falsely trip the lignin sensor.

On the other hand, the stiffness sensor, which is typically used to separate cardboard from other paper grades, is incapable of recognizing a stack of office papers on the conveyor that produce high stiffness similar to a paperboard. In addition, the gloss sensor is used to separate glossy paper from other papers where as the color sensor measures the radiation of the paper surface and is commonly used to identify WPs.

High capital costs are required for the implementation of existing automated sorting systems that deploy state-ofthe-art technology, namely, NIR, IR, and X-ray. Despite the feasibility for high-throughput volumes of these technologies (Dzuraidah et al. 2006), their use is generally not economical for small-scale operators. These systems can only segregate two types of paper at a time. Moreover, no image processing and/or intelligent techniques are used to extract the features or characteristics of the paper objects. The recycling volume of the Malaysian local paper recycling facilities can be categorized as low to medium (Dzuraidah et al. 2006). The correct real-time identification of the sample before it reaches the actuation station remains a challenge because (1) different types of paper and board samples are mixed in a waste stream and (2) color, chemical composition, coating, as well as prints in black and white and colors, vary widely. This limitation is primarily attributed to the lack of satisfactory sensors and sensor fusion algorithms for real-time sample identification. Consequently, a new arena of research in recyclable waste paper sorting using a webcam sensor-based computer vision system is unveiled, which is the key motivation for the development of a smart vision sensing (SVS) system using a webcam as an image sensor that can segregate different grades of paper. Using the SVS system, the texture information from the paper object image is considered to determine the paper grade, which overcomes the major drawback of the previous recyclable waste paper sorting techniques. Several methods involving image processing and artificial intelligence techniques have been developed for conducting empirical studies on the different methods of validating the effectiveness of the webcam sensor-based SVS system in real-time operation.

First, the recyclable waste paper grade identification was developed using co-occurrence features (Rahman et al. $2009 \mathrm{~b}$ ). The method described in this work primarily transforms the original image into a quantized image,calculates the co-occurrence matrix from the quantized image, calculates the energy for the co-occurrence matrix, develops a rule-based classifier, and then identifies the grade of the paper object. Despite its success rate of more than $90.67 \%$, which is up to the mark, the method is unsuitable for realtime implementation because of its high computational time.

Second, the template matching/DNA computing algorithm was considered for waste paper sorting (Rahman et al. 2009c, 2012a). The technology for DNA computer is under development (Watada and Rohani 2008), but the role of DNA computing technology in applications has increased significantly over the last few years (Yeh and Chu 2008). The main emphasis of this work was on the development of a novel DNA computing method for a recyclable waste paper sorting system. The method described in this work mainly transforms the pixel value to red-green-blue (RGB) strings and the RGB strings to DNA strands and then simulates basic biological operations to identify the grade of the paper object. Based on the experiment, the performance of the vision system is found to be significantly affected by the lighting arrangement and template size. The DNA computing algorithm was simulated using a template matching method because the DNA computer is still under development. Despite the classification success rate of the template matching method at $94.67 \%$, the method is also difficult to implement because of the high computational time involved. However, the vital drawback of template matching is efficiently mitigated by the massive parallelism of DNA computing.

Third, the dominant color-based recyclable waste paper grade identification method was developed (Rahman et al. 2011). The proposed system performance in correct paper grade identification exceeds $93 \%$, with a throughput of 28,800 paper objects per hour and a $457.2 \mathrm{~mm}\left(18^{\prime \prime}\right)$ conveyor belt width. The weight of the throughput depends on the size and grade of the paper objects. In this method, the performance of the vision system is found to be influenced by the lighting arrangement. Thus, to achieve the best performance using this method, lighting consistency must be maintained during the enrollment and identification phases of the system.

Fourth, the recyclable waste paper grade identification method for the SVS system was developed based on the window features using the case-based reasoning (CBR) 
approach (Rahman et al. 2012b). The method described involves the window-based subdivision of the paper image into $\mathrm{N}$-cells, the construction of $\mathrm{N}$-candidate template for $\mathrm{N}$-cells, the calculation of matching scores of reference templates for the $\mathrm{N}$-cell paper image, and the application of matching scores to identify the grade of the paper object. The SVS system performance in correct paper grade identification is $95.17 \%$, with an estimated throughput of 21,600 paper objects per hour and a $457.2 \mathrm{~mm}\left(18^{\prime \prime}\right)$ conveyor belt width. The weight of the throughput depends on the size and grade of the paper objects. The method was trained using numerous reference templates under different lighting conditions, which overcame the need to maintain lighting consistency during the enrollment and identification phases. Moreover, the algorithm provides robust and fast results because the proposed method avoids the additional computational burden for preprocessing given that only two features, mode and energy, of the RGB components are used to identify the dominating color value of the paper object image. The proposed method can identify three major paper grades, WP, old news paper (ONP), and OCC, using the CBR approach with coalescing window-based subdivision technique and first-order window features.

Fifth, the recyclable waste paper grade identification method for the SVS system was developed based on chromaticity (Rahman et al. 2010, 2012c). The method described mainly involves the conversion of RGB pixel value to the hue, saturation, and intensity (HSI) color scale, the window-based subdivision of the paper image into $\mathrm{N}$-cells, the construction of $\mathrm{N}$-candidate template for $\mathrm{N}$-cells, the calculation of the matching scores of reference templates for the N-cells paper image, and the matching of scores to identify the grade of the paper object. The proposed system performance for correct paper grade identification exceeds $90 \%$, with an estimated throughput of 18,000 paper objects per hour and a $457.2 \mathrm{~mm}\left(18^{\prime \prime}\right)$ conveyor belt width. The weight of the throughput depends on the size and grade of the paper objects. The proposed method did not utilize the intensity or brightness of the paper image, which overcame the constraint of maintaining lighting consistency during the enrollment and identification phases. Moreover, the algorithm provides robust and fast results because the proposed method avoids the additional computational burden for preprocessing and only three features (mode of hue, mean of hue and mean of saturation) are used to identify the dominant color value of the paper object image.

\section{Overall performance analysis and discussion}

The key parameters that are considered to measure the overall performance of the real-time SVS system are accuracy, speed, robustness, flexibility, reliability, and cost-effectiveness (Pham and Alcock 2003). The accuracy of waste paper grade identification is a vital parameter to validate the acceptability of the method. Secondary to accuracy, the speed or the optimum computational load of the method makes the system viable for implementation in real-time applications. The system must provide a robust decision in rough environments; for instance, the system must be insensitive to variable light, vibrations, and dust. The system must be flexible to the user, and the users must be able to change the settings of the system as required. For reliability, the system is supposed to detect its failure automatically and then raise the alarm with necessary suggestions. One of the main obstacles to the widespread adoption of the real-time SVS system is the cost of development, implementation, and maintenance. The performance-to-price ratio must be high to adopt the real-time SVS system in real-world applications.

Considering the key parameters of performance, different waste paper grade identification methods are developed incrementally for the real-time SVS system to overcome the constraints presented by the previous methods. The details of the developed methods with their classification success rates are shown in Table 4. The existing automated sorting systems published in the literature that deploy stateof-the-art technology, such as NIR, IR, and X-ray, require high investments, remain complex, and sometimes offer limited reliability, as shown in Table 3. The paper sorting performance in the industry reaches $80 \%$ for both MSS and TiTech systems (Remade Scotland 2005). All systems can only segregate two types of paper at a time. Moreover, no image processing or intelligent techniques are used to extract the features or characteristics from the paper objects.

Kumar (2007) conducted his experiment offline and integrated the outcomes of four sensors, namely, lignin, gloss, stiffness, and the Nikon D50 Digital SLR camera. For color information, the $\mathrm{L} \times \mathrm{a} \times \mathrm{b}$ color space was used, which involved two color space conversions, from the RGB color space to the XYZ color space and from the $\mathrm{XYZ}$ color space to the $\mathrm{L} \times \mathrm{a} \times \mathrm{b}$ color space. Moreover, the color variance parameters were used as partial features of the feature vector. On the other hand, the webcam sensor-based SVS system used either the RGB or the HSI color space, making the SVS system viable for implementation in real-time applications with a low-cost solution.

Co-occurrence features (Rahman et al. 2009b): The co-occurrence feature method offers over $90 \%$ accuracy in the waste paper grade identification. The method uses the rule-based classifier, which is considerably faster than other developed methods. However, the computational time required to create a co-occurrence matrix is 
Table 4 Results of the existing automated sorting systems published in literature

\begin{tabular}{|c|c|c|c|c|}
\hline & $\begin{array}{l}\text { Techniques applied } \\
\text { for identification }\end{array}$ & Types of sensor & Features & $\begin{array}{l}\text { Classification } \\
\text { success rate } \\
(\%)\end{array}$ \\
\hline $\begin{array}{l}\text { TiTech systems (Remade } \\
\text { Scotland 2005) }\end{array}$ & Not mentioned & $\begin{array}{l}\text { NIR, CMYK sensor and } \\
\text { color camera }\end{array}$ & $\begin{array}{l}\text { Materials, shape, color, texture, and four } \\
\text { color printing }\end{array}$ & 80 \\
\hline $\begin{array}{l}\text { MSS systems (Remade } \\
\text { Scotland 2005) }\end{array}$ & Not mentioned & $\begin{array}{l}\text { NIR, color sensor, gloss, } \\
\text { and lignin }\end{array}$ & $\begin{array}{l}\text { The sensor measures the intensity of the } \\
\text { material's fluorescence at a specific } \\
\text { wavelength in the ultraviolet light }\end{array}$ & 80 \\
\hline \multirow{2}{*}{$\begin{array}{l}\text { Mechatronic design of a } \\
\text { waste paper sorting system } \\
\text { for efficient recycling } \\
\text { (Kumar 2007) }\end{array}$} & $\begin{array}{l}\text { Artificial neural } \\
\text { network }\end{array}$ & \multirow{2}{*}{$\begin{array}{l}\text { Four sensors: lignin, gloss, } \\
\text { stiffness, and Nikon D50 } \\
\text { digital SLR camera as a } \\
\text { color }\end{array}$} & \multirow{2}{*}{$\begin{array}{l}\text { (1) Average lignin value, (2) gloss meter } \\
\text { reading, (3) deflection in the upward } \\
\text { direction, (4) deflection in the downward } \\
\text { direction, (5) color variance parameter I, } \\
\text { (6) color variance parameter II }\end{array}$} & 36.6 \\
\hline & $\begin{array}{l}\text { Fuzzy inference } \\
\text { system algorithm }\end{array}$ & & & 90.4 \\
\hline $\begin{array}{l}\text { Co-occurrence features } \\
\text { (Rahman et al. 2009b) }\end{array}$ & $\begin{array}{l}\text { Rule-based } \\
\text { classifier }\end{array}$ & \multirow{5}{*}{$\begin{array}{l}\text { Logitech QuickCam Pro } \\
\text { 4,000 web camera } \\
\text { (webcam sensor) }\end{array}$} & Energy for the co-occurrence matrices & 90.67 \\
\hline $\begin{array}{l}\text { DNA computing algorithm/ } \\
\text { template matching } \\
\text { (Rahman et al. 2009c, } \\
\text { 2012a) }\end{array}$ & Template matching & & RGB string & 94.67 \\
\hline $\begin{array}{l}\text { Dominated color (Rahman } \\
\text { et al. 2011) }\end{array}$ & $\begin{array}{l}\mathrm{KNN} \text {, absolute } \\
\text { distance metric }\end{array}$ & & $\begin{array}{l}\text { First-order features: energy, mode, histogram } \\
\text { tail length on the dark side, histogram tail } \\
\text { length on the light side, lower quartile, and } \\
\text { upper quartile }\end{array}$ & 93 \\
\hline $\begin{array}{l}\text { Window features with HSI } \\
\text { color space (Rahman et al. } \\
\text { 2010, 2012c) }\end{array}$ & $\begin{array}{l}\text { Chromaticity: } \\
\text { window-based } \\
\text { subdivision, } \\
\text { distance, and } \\
\text { voting }\end{array}$ & & $\begin{array}{l}\text { Mode of hue, mean of the hue and mean of } \\
\text { the saturation }\end{array}$ & 91.07 \\
\hline $\begin{array}{l}\text { Window features with RGB } \\
\text { color space (Rahman et al. } \\
\text { 2012b) }\end{array}$ & $\begin{array}{l}\text { CBR approach: } \\
\text { case base } \\
\text { reasoning }\end{array}$ & & Mode and energy of the RGB components & 95.17 \\
\hline
\end{tabular}

$N I R$ near infrared, $C M Y K$ cyan, magenta, yellow, and key (black), $C B R$ case-based reasoning, $R G B$ red green blue, $H S I$ hue saturation intensity, $K N N$ K-nearest neighbor, DNA deoxyribonucleic acid

excessively large and is the main constraint in the implementation of the system in real-time applications. Moreover, the method uses the rule-based classifier; hence, it could not handle a new subcategory of paper grades. For handling new subcategories of the paper objects, new rules must be created.

DNA computing algorithm/template matching (Rahman et al. 2009c, 2012a): The average maximum classification success rate of the template matching system is $94.67 \%$, with a cell size of $5 \times 5$ pixels. In real-time implementation, the template matching technique is ineffective and inconvenient because of high computational time and lighting sensitivity. The performance of the template matching method largely depends on the lighting consistency during the enrollment and identification phases. For template matching, a $5 \times 5$ template consists of 25 pixels, and for each pixel, the RGB string length is 4-16. Thus, the RGB string length for the $5 \times 5$ template is $100-400$. As a consequence, 100-400 comparisons are made between one reference template and one cell image template.
Dominant color with first-order features (Rahman et al. 2011): The dominant color-based method offers $93 \%$ average success rate in waste paper grade identification. The performance of this method depends on the lighting consistency during the enrollment and identification phases, similar to the template matching method. The success rate is also influenced by proper reference database creation.

Window features (WF) (Rahman et al. 2010, 2012b, c): The WF-based method has been developed for both the RGB and HSI color spaces. Additional computation time is needed for the WF method with an HSI color space because of the conversion from the RGB color space to the HSI color space. On the other hand, the WF method with an RGB color space overcomes the problem of additional color space conversion time. Moreover, the WF method with an RGB color space is superior to the WF method with an HSI color space in terms of throughput, as shown in Table 4. The WF method with an HSI color space offers a maximum success rate of $95 \%$ with a $3 \times 3$ cell size, 
$92 \%$ with a $5 \times 5$ or $8 \times 8$ cell size, and $90 \%$ with $3 \times 3$ cell size for WP, ONP, and OCC, respectively. The average classification success rate of this method is $91.07 \%$, with a cell size of $3 \times 3$ pixels. On the other hand, the WF method with an RGB color space offers a maximum success rate of $94 \%$ with a $3 \times 3$ cell size, $94 \%$ with a $5 \times 5$ cell size, and $98 \%$ with a $3 \times 3$ cell size for WP, ONP, and OCC, respectively. The average classification success rate of this method is $95.17 \%$, with cell size of $3 \times 3$ pixels. Figure 5 compares the performance of both methods. For ONP, the WF method with an HSI color space performs better than the WF method with the RGB color space. On the other hand, for WP, the WF method with an RGB color space performs s better than the WF method with an HSI color space.

One major deficiency is observed in both WF-based methods involving the CBR approach and the chromaticity-based system. The subdivisions of the paper object image into N-cells are shown in (Rahman et al. 2010, 2012 b, c). All cells are considered for feature calculation using the CBR approach and the chromaticity-based system. These cells are discarded because all background cells are unnecessary for paper grade identification in the WFbased system. The efficiency of the WF-based (CBR approach and chromaticity-based systems) system is improved in terms of computational time because of the removal of background cells.

Table 5 illustrates the relative comparison among different methods developed for SVS systems based on accuracy, speed, robustness, flexibility, reliability, and cost-effectiveness. First, the seven methods are examined using 100 paper samples. The co-occurrence features (Rahman et al. 2009b) and DNA computing algorithm methods (Rahman et al. 2009c, 2012a) offer good results in terms of identification, but both methods are discarded because of high computational loads and the need to maintain lighting consistency during the enrollment and identification phases, which results in low robustness. Moreover, user customization for new subcategories is very difficult, resulting in low flexibility. Considering that the dominant color, first-order features-based method (Rahman et al. 2011) takes moderate time because of paper object image preprocessing, further investigations are performed using a greater number of paper samples of up to 500 each for WP, ONP, and OCC. In this method, 17 first-order features are examined, and 6 more promising features are selected. The dominant color-based method offers low robustness because lighting consistency is essential to obtain a high identification rate. For enrollment, the method offers more flexibility than the two previous methods. The dominant color (Rahman et al. 2011) and WF-based methods (Rahman et al. 2010, 2012b, c) offer high robustness because all methods work in rough environments. These methods also offer high reliability and costeffectiveness because they provide the necessary information regarding unrecognized paper objects, and the costs of development, implementation, and maintenance are low. For further investigation of the accuracy and robustness, the number of paper samples is increased from 100 to 500 for these methods.

\section{Conclusion}

Waste papers are segregated in the godown or paper manufacturing industry. In paper manufacturing, a specific target grade of paper is segregated. For instance, the newsprint paper industry needs only ONP, the WP industry needs only WP, and the corrugated cardboard industry needs ONP or OCC to produce a high-quality product. The
Fig. 5 Paper grade identification success rates comparison between window features with RGB (red green blue) and window features with HSI (hue saturation intensity) color spaces. Source: Rahman et al. (2012b)

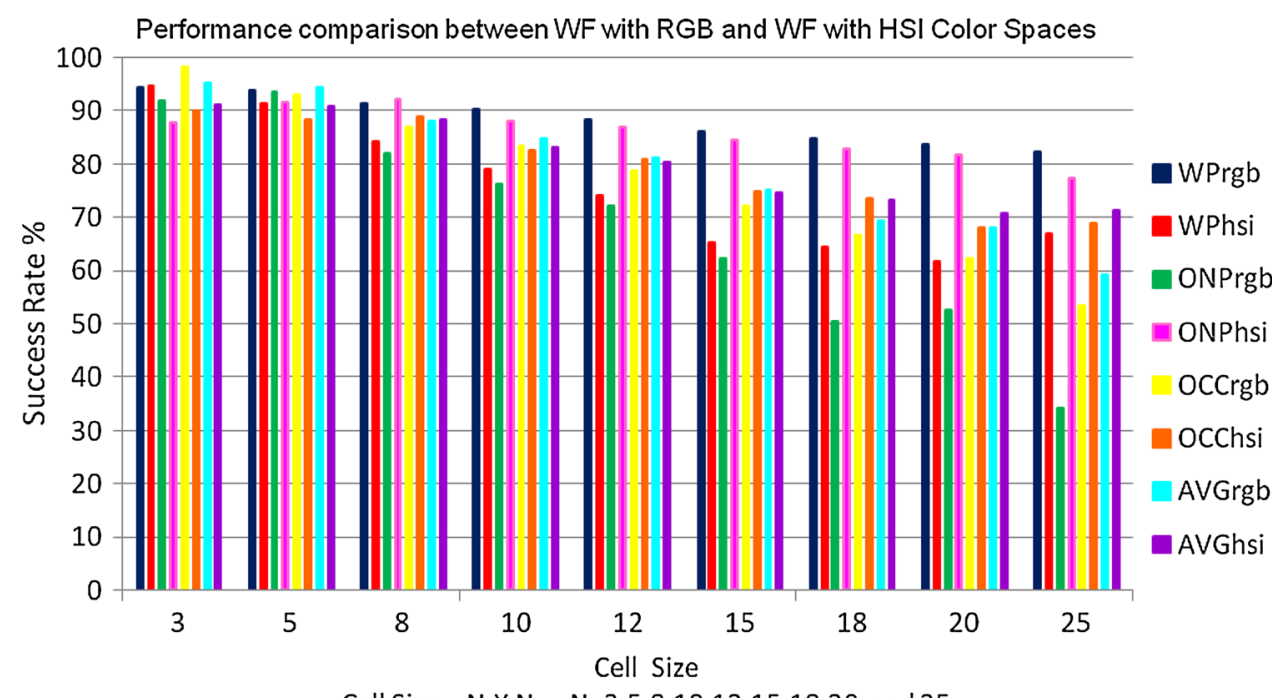

Cell Size $=\mathrm{N} X \mathrm{~N}, \quad \mathrm{~N}=3,5,8,10,12,15,18,20$, and 25 
Table 5 Overall performance of the of the SVS system with different methods

\begin{tabular}{|c|c|c|c|c|c|c|c|}
\hline Sl. no. & Various methods & Accuracy & Fast & Robust & Flexibility & Reliability & Cost-effective \\
\hline 1. & Co-occurrence features & $\mathrm{H}$ & $\mathrm{L}$ & M & $\mathrm{L}$ & $\mathrm{H}$ & $\mathrm{H}$ \\
\hline 2. & DNA computing algorithm/template matching & $\mathrm{H}$ & $\mathrm{L}$ & $\mathrm{L}$ & $\mathrm{L}$ & $\mathrm{H}$ & $\mathrm{L}$ \\
\hline 3. & Dominated color & $\mathrm{H}$ & M & $\mathrm{H}$ & $\mathrm{H}$ & $\mathrm{H}$ & $\mathrm{H}$ \\
\hline 4. & Window features with HSI (chromaticity) & $\mathrm{H}$ & $\mathrm{L}$ & $\mathrm{H}$ & $\mathrm{H}$ & $\mathrm{H}$ & $\mathrm{H}$ \\
\hline 5. & Window features with RGB (CBR approach) & $\mathrm{H}-\mathrm{V}$ & $\mathrm{L}$ & $\mathrm{H}$ & $\mathrm{H}$ & $\mathrm{H}$ & $\mathrm{H}$ \\
\hline
\end{tabular}

$H$ high, $L$ low, $M$ moderate, $H-V$ high to very high, $H S I$ hue-saturation-intensity color model, $R G B$ red-green-blue color model, $C B R$ casebased reasoning

separation of one type of paper from another is important in this industry. Hence, the paper industry may choose a specific sensor-based paper sorting system, such as a stiffness sensor for OCC, a lignin sensor for ONP, a gloss sensor for glossy paper, a color sensor for WP, and so on. On the other hand, suppliers provide different types of paper to the respective paper industries from the godown. Hence, a multigrade paper sorting system is essential in the godown stage. Given the weaknesses of lignin, stiffness, gloss, color, NIR, and MIR sensor-based waste paper sorting systems, a webcam sensor-based recyclable waste paper sorting system is found to be one of the best low-cost alternatives.

Acknowledgments The project is sponsored and supported by the Universiti Kebangsaan Malaysia grants UKM-MI-OUP-2011.

\section{References}

Ahmed MT (2010) Life cycle analysis in developing countries an Egyptian perspective. Environmental impact assessment unit. Suez Canal University, Ismailia, 2010 (January 24, 2011)

Asia Pro Eco Program (2006) Feeding China's expanding demand for wood pulp: a diagnostic assessment of plantation development, fiber supply, and impacts on natural forests in China and in the South East Asia Region. Malaysia Report. ISBN 979-24-4676-1

Bialski A, Gentile C, Sepall O (1978) Paper sorting method, US Patent No. 4,124,168

Bialski A, Gentile C, Sepall O (1980) Paper sorting apparatus, US Patent No. 4,236,676

Bruner RS, Morgan DR, Kenny GR, Gaddis PG, Lee D, Roggow JM (2003) System and method for sensing white paper, US Patent No. 6,570,653

Bystrom S, Lonnstedt L (2000) Paper recycling: a discussion of methodological approaches. Elsevier Resour Conserv Recycl 28(2000):55-65

Chakravarthi KK (2006) Development of online stiffness sensor for high speed sorting of recovered paper. Master's thesis. North Carolina State University, Raleigh, NC, USA

Chandini CM (2001) Design of lignin sensor for identification of waste paper grades for an automatic waste paper sorting system. Master's thesis. North Carolina State University, Raleigh, NC, USA

Chen HW, Yu RF, Liaw SL, Huang WC (2010) Information policy and management framework for environmental protection organization with ecosystem conception. Int J Environ Sci Technol $7(2): 313-326$
Doak AG, Roe MG, Kenny GR (2006a) Multi-grade object sorting system and method, US Patent No. 2006/0109473

Doak AG, Roe MG, Kenny GR (2006b) Multi-grade object sorting system and method, US Patent No. 7019822

Doak AG, Roe MG, Kenny GR (2007a) Multi-grade object sorting system and method, US Patent No. 7173709

Doak AG, Roe MG, Kenny GR (2007b) Multi-grade object sorting system and method, US Patent No. US2007/0002326

Dzuraidah AW, Hussain A, Scavino E, Mustafa MM, Basri H (2006) Development of a prototype automated sorting system for plastic recycling. Sci Publ Am J Appl Sci 3(7):1924-1928

Eixelberger R, Friedl P, Gschweitl K (2003) Method and apparatus for sorting waste paper of different grades and conditions, US Patent No. 6,506,991

Ekvall T (1999) Key methodological issues for life cycle inventory analysis of paper recycling. Elsevier J Clean Prod 7(1999):281-294

European Commission (2001) The EU Commission's reference document on best available techniques in the pulp and paper industry

Faibish S, Bacakoglu H, Goldenberg AA (1997) An eye-hand system for automated paper recycling. In: Proceedings of the IEEE International Conference on Robotics and Automation, Albuquerque, New Mexico, pp 9-14

Forstall F (2002) Industry and trade summary. United States International Trade Commission, Washington, DC 20436, USITC Publication 3490, pp 26-27

Grubbs M, Kenny GR, Gaddis PG (2001) Paper Sorting System, US Patent No. 6,250,472

Gschweitl; Heinz K (1998) Method for sorting waste paper, European Patent EP0873797

Hannan MA, Arebey M, Abdullah H, Begum RA, Basri H (2011) Solid waste truck monitoring and management using RFID, GIS and GSM. J Appl Sci Res 7(12):1961-1964

Holz E, Hutzler H (1986) Apparatus for dissolving and sorting waste paper, US Patent No. 4,632,320

Hottenstein FA, Kenny GR, Friberg T, Jackson M (2000) High-speed automated optical sorting of recovered paper. In: Proceedings of TAPPI recycling symposium, 2000, vol 1, Atlanta, GA, pp 149-158

Karunakaran M, Ramasubramanian MK, Venditti RA (2003) Mechatronic design and control of a waste paper sorting system for efficient recycling: development of a lignin sensor to distinguish recovered paper grades at high speed. In: APPI Technical Conference, 2003

Kayo C, Hashimoto S, Moriguchi Y (2012) Paper and paperboard demand and associated carbon dioxide emissions in Asia through 2050. J Ind Ecol 16(4):529-540

Khalfan Z (2002) Optical paper sorter. US Patent No. 6,335,501

Khalfan Z, Greenspan S (2006a) Optical paper sorting method device and apparatus, US Patent No. 2006/0124511

Khalfan Z, Greenspan S (2006b) Optical paper sorting method device and apparatus, US Patent No. 7,081,594 
Kumar RGP (2007) Mechatronic design of a waste paper sorting system for efficient recycling. Dissertation of the Master of Science, Mechanical Engineering. North Carolina State University, Raleigh, NC

Laurijssen J, Marsidi M, Westenbroek A, Worrell E, Faaij A (2010) Paper and biomass for energy? The impact of paper recycling on energy and $\mathrm{CO}_{2}$ emissions. Elsevier Resour Conserv Recycl 54(12):1208-1218

Mallapragada V (2004) Online lignin sensor for high speed sorting of newsprint from mixed waste. Master's thesis. North Carolina State University, Raleigh, NC, USA

Mallapragada V, Ramasubramanian MK, Venditti RA (2004) A compact, high speed lignin sensor for the automated sorting of newsprint from mixed waste. In: Tappi Spring Technical Conference, 2004

MSS Optical sorting Systems (2009). http://www.magsep.com/. Accessed 15 Aug 2009

MSS Paper Sorting Systems (2009). http://www.recyclingtoday.com/ news/news.asp?ID=742. Accessed 15 Aug 2009

Ortner H, Bahr T, Musselmann W (1980) Process and apparatus for treating waste paper, US Patent No. 4,231,526

Paper Competitors (2009). http://separation.wikispaces.com/Paper+ Competitors. Accessed 10 Jul 2009

Paper Grades (2009). http://www.paperonweb.com/ppmanf.htm. Accessed 12 Feb 2009

Paper Recycling (2009). SPM paper recycling. Sdn Bhd, Kuala Lumpur, Malaysia. http://spmholdings.com.my/index.php?page= staticpages/paper. Accessed 10 Nov 2009

Paper Recycling (2010). Malaysian newsprint industries. http://www. newsprint.com.my/. Accessed 10 Apr 2010

Pati RK, Vrat P, Kumar P (2006) Economic analysis of paper recycling visa-vis wood as raw material. Int $\mathrm{J}$ Prod Econ 103(489-508):2006

Pati RK, Vrat P, Kumar P (2008) A goal programming model for paper recycling system. ScienceDirect Omega. Int J Manag Sci 36(2008):405-417

Pellenc (2009) Paper sorting Company. http://www.pellencst.com/en/ 1/products. Accessed 15 Aug 2009

Petek J, Glavic P (1996) An integral approach to waste minimization in process industries. Elsevier Resour Conserv Recycl 17(169188): 1996

Pham DT, Alcock RJ (2003) Chap. 1 Automated visual inspection and artificial intelligence and Chap. 7 Industrial inspection systems. Smart inspection system-techniques and applications of intelligent vision. Academic Press, Great Britain, pp 4-6, and 204-205

Rahman MO, Hannan MA, Scavino E, Hussain A, Basri H (2009a) An efficient paper grade identification method for automatic recyclable waste paper sorting. Eur J Sci Res 25(1):96-103

Rahman MO, Hussain A, Scavino E, Hannan MA, Basri H (2009b) Segregating recyclable waste papers using co-occurrence features. In: The 9th WSEAS international conference on applied computer science (ACS'09), 2009, Genova, Italy, pp 187 $-191$

Rahman MO, Hussain A, Scavino E, Hannan MA, Basri H (2009c) Recyclable waste paper sorting using template matching. LNCS, vol 5857. Springer, Berlin, pp 467-478

Rahman MO, Hussain A, Basri NEA, Scavino E, Basri H, Hannan MA (2010) Waste paper grade identification system using window features. J Comput Inf Syst 6(7):2077-2091

Rahman MO, Hussain A, Hannan MA, Scavino E, Basri H (2011) Intelligent computer vision system for segregating recyclable waste papers. Expert Syst Appl: 10398-10407. doi:10.1016/j. eswa.2011.02.112

Rahman MO, Hussain A, Scavino E, Hannan MA, Basri H (2012a) Object identification using DNA computing algorithm. In: WCC
2012 IEEE world congress on computational intelligence, 10-15 June 2012, Brisbane, Australia, pp 1454-1460

Rahman MO, Hussain A, Scavino E, Hannan MA, Basri H (2012b) Real-time waste paper grading using CBR approach. Int J Innov Compuy Inf Control 8(1(A)):471-488

Rahman MO, Hussain A, Basri NEA, Scavino E, Basri H, Hannan MA (2012c) Chromaticity based waste paper grade identification. Accepted for Publication in International Arab Journal of Information Technology (IAJIT), Vol.9, No.5, September 2012, First Online Publication

Ramasubramanian MK, Venditti RA, Ammineni CM, Mallapragada M (2005) Optical sensor for noncontact measurement of lignin content in high-speed moving paper surfaces. IEEE Sens J 5(5):1132-1139

Ramasubramanian MK, Venditti RA, Gillella PK (2008) Sensor systems for high speed intelligent sorting of waste paper in recycling. http://www.osti.gov/bridge/servlets/purl/919471VGwxA0/919471.PDF. Accessed 20 Feb 2008

Ramasubrmanian MK, Venditti RA, Katuri KC (2007) Behavior of paper on a high-speed conveyor subjected to air jet impingement $-\mathrm{a}$ method for bending stiffness estimation. Mech Mater Struct 2(2):201-219

RedWave (2009) BT-Wolfgang Binder. http://www.redwave.at/ altpapierrecycling/. Accessed 10 Sept 2009

Remade Scotland (2005) Initial business case for utilisation of automated optical paper sorting technology. Caledonian Environment Centre, Glasgow Caledonian University. http://www.remade.org.uk/files/ InitialBusinessCaseforUtilisationofAutomatedOpticalPaperSorting Technology_16122222124.pdf. Accessed 25 Feb 2008

Ruwaard JMB, Wassenhove LNV, Gabel HL, Weaver PM (1996) An environmental life cycle optimization model for the European pulp and paper industry. Omega Int J Mgmt Sci 24(6):615-629

Sandberg NH (1932) Sorting device for waste paper, US Patent No. $1,847,265$

Schmidt JH, Holm P, Merrild A, Christensen P (2007) Life cycle assessment of the waste hierarchy - a Danish case study on waste paper. ScienceDirect, Elsevier. Waste Manag 27(2007):1519-1530

Spencer MW (1994) Waste paper disintegration, classification and pulping system, US Patent No. 5,324,389

TITECH autosort (2009). http://www.titech.com/recycling-equipment/ titech-autosort-10715. Accessed 15 Aug 2009

Venditti RA, Ramasubramanian MK, Katuri KC (2005) Development of a bending stiffness sensor for the automated sorting of recovered paper. In: Engineering, Pulping, and Environmental Conference, Philadelphia, 2005

Venditti RA, Ramasubramanian MK, Kalyan CK (2007) A noncontact sensor for the identification of paper and board samples on a high speed sorting conveyor. J Tech Assoc Aust N Z Pulp Paper Ind 60(5):366-371

Villanueva A, Wenzel H (2007) Paper waste-recycling, incineration or landfilling? A review of existing life cycle assessments. ScienceDirect, Elsevier. Waste Manag 27(2007):S29-S46

WasteCap (2008) WasteCap of Massachusetts, 68 Hopkinton Road, Westboro, MA 01581, March 2008. http://www.wastecap.org/ wastecap/commodities/paper/paper.htm. Accessed 15 July 2009

Watada J, Rohani AB (2008) DNA computing and its applications. In: Eighth international conference on intelligent systems design and applications, 978-0-7695-3382-7/08 IEEE, pp 288-294

Würtz H, Breum NO (1997) Exposure to microorganisms during manual sorting of recyclable paper of different quality. Ann Agric Environ Med 4(1997):129-135

Yeh C-W, Chu C-P (2008) Molecular verification of rule-based systems based on dna computation. IEEE Trans Knowl Data Eng 20(7):965-975

Zaman AU (2010) Comparative study of municipal solid waste treatment technologies using life cycle assessment method. Int $\mathbf{J}$ Environ Sci Technol 7(2):225-234 